\title{
REGISTROS DE SESSÃO TERAPÊUTICA: RELATO, GRAVAÇÃO OU TRANSCRIÇÃO? CONSIDERAÇÓES SOBRE AS DIFERENÇAS ENTRE OS REGISTROS
}

\author{
REGISTERING PSYCHOTHERAPY SESSIONS: \\ REPORT, RECORD OR TRANSCRIPTION? \\ CONSIDERATIONS ON THE DIFFERENCES BETWEEN
} THE REGISTRIES

¿REGISTRO DE SESIONES DE PSICOTERAPIA: INFORMES, GRABACIÓN DE AUDIO O TRANSCRIPCIÓN? CONSIDERACIONES ACERCA DE LAS DIFERENCIAS ENTRE LOS REGISTROS

Milena da Rosa Silva* Eduarda Duarte de Barcellos** Livia Fração Sanchez*** Denise Steibel ${ }^{* * * *}$ Paula de Paula Fernandes**** Paula von Mengden Campezatto***** Lisiane Geremia ${ }^{* * * * * *}$ Regina Pereira Klarmann ${ }^{* * * * * * *}$

* Universidade Federal do Rio Grande do Sul, Porto Alegre, RS, Brasil; IEPP - Instituto de Ensino e Pesquisa em Psicoterapia, Porto Alegre, RS, Brasil.

** Universidade Federal do Rio Grande do Sul, Porto Alegre, RS, Brasil.

*** IEPP - Instituto de Ensino e Pesquisa em Psicoterapia, Porto Alegre, RS, Brasil; Pontifícia Universidade Católica do Rio Grande do Sul, Porto Alegre, RS, Brasil.

**** Universidade Federal do Rio Grande do Sul, Porto Alegre, RS, Brasil; IEPP - Instituto de Ensino e Pesquisa em Psicoterapia, Porto Alegre, RS, Brasil.

***** Universidade Federal do Rio Grande do Sul, Porto Alegre, RS, Brasil.

****** IEPP - Instituto de Ensino e Pesquisa em Psicoterapia, Porto Alegre, RS, Brasil; Pontifícia Universidade Católica do Rio Grande do Sul, Porto Alegre, RS, Brasil.

******* IEPP - Instituto de Ensino e Pesquisa em Psicoterapia, Porto Alegre, RS, Brasil.

*********IEPP-Instituto deEnsino ePesquisa em Psicoterapia, PortoAlegre, RS, Brasil;SPPA-Sociedade Psicanalítica de Porto Alegre, Porto Alegre, RS, Brasil. 


\section{ResUmo}

A temática da gravação das sessốes de psicoterapia não apresenta consenso na literatura. Alguns autores referem à possibilidade de ampliação dos conhecimentos e entendimento mais aprofundado das sessóes, destacando a importância da gravação para estudos de processo psicoterápico. Outros enfatizam a exposição dos pacientes e a interferência negativa da gravação no processo e no desenvolvimento da aliança terapêutica. $\mathrm{O}$ presente estudo teve como objetivo examinar distintas formas de registro de sessóes de psicoterapia psicanalítica. Consiste em levantamento das diferenças e especificidades do registro em áudio, da transcrição e do relato pela memória do psicoterapeuta de uma sessão de psicoterapia. A fonte de informaçóes é oriunda de três sessóes consecutivas de um tratamento de uma jovem de 19 anos, as quais foram analisadas qualitativamente por um grupo de pesquisadores formado por psicanalista, psicólogos-psicoterapeutas e estudantes de psicologia. A principal diferença encontrada foi a existência, no relato da terapeuta, de contextualizaçóes e sentimentos contratransferenciais que davam vivacidade ao material. A experiência de ouvir a gravação foi considerada cansativa pelos pesquisadores, porém trouxe a possibilidade de escutar o tom da voz e perceber aspectos afetivos da relação entre terapeuta e paciente. Estabeleceram-se considerações sobre os conteúdos presentes nas transcriçóes e ausentes nos relatos de memória, identificando que a essência do material permanecia a mesma, embora transformado pela experiência da terapeuta.

Palavras-chave: psicoterapia; gravação em áudio; relato; psicanálise.

\section{Abstract}

The theme of recording sessions is not a consensus in the literature. Authors mention the possibility of expanding knowledge and deeper understanding of what goes on in sessions, highlighting the importance of recording them for studies of the psychotherapeutic process. Others emphasize the patient's exposure and negative interference of recording in the process and the development of therapeutic alliance. This present study aimed to examine different ways of recording sessions of psychoanalytic psychotherapy. Consists on a survey of differences and particularities of audio recording, transcription and reporting by psychotherapist's memory of a psychotherapy session. The source of information is coming from three consecutive sessions of a treatment of a 19 years old patient, which were analyzed qualitatively by a research group formed by psychoanalysts, psychotherapists, psychologists and psychology students. The main difference was the existence of contextualization and countertransference feelings in the 
report by psychotherapist memory, which gave vitality to the material. The experience of listening the audio was considered tiresome, but brought the possibility of listening the manner and voice tone between therapist and patient. Considerations were settled about contents listed in the transcripts but not in report by psychotherapist memory, identifying that material's essence remained the same, although transformed by therapist's experience.

Keywords: psychotherapy; audio recording; reporting session; psychoanalysis.

\section{Resumen}

El tema de la grabación de sesiones de psicoterapia no muestra consenso en la literatura. Algunos autores se refieren a la posibilidad de ampliar el conocimiento y la comprensión más profunda de las sesiones, destacando la importancia de la grabación para el estudio del proceso de la psicoterapia. Otros enfatizan la exposición de los pacientes y la interferencia negativa de la grabación en el proceso psicoterápico y en el desarrollo de la alianza terapéutica. El presente estudio tuvo como objetivo examinar las formas distintas de registro de psicoterapia psicoanalítica. Consiste en levantamiento de las diferencias y particularidades de la grabación en audio, transcripción y presentación de informes por parte de la memoria del psicoterapeuta de una sesión de psicoterapia. La fuente de información se compone de tres sesiones consecutivas de un tratamiento de una paciente de 19 años de edad, las cuales fueron analizadas cualitativamente por un grupo de investigación formado por psicoanalistas, psicoterapeutas, psicólogos y estudiantes de psicología. Se encontró que la principal diferencia fue la existencia en los informes del terapeuta de contextualizaciones y sentimientos contratransferenciales que dieron vida al material. La experiencia de escuchar el audio fue considerada por los investigadores fatigosa, pero trajo la posibilidad de escuchar el tono de voz y darse cuenta de la relación afectiva entre terapeuta y paciente. Consideraciones fueran establecidas sobre el contenido presente en las transcripciones y ausentes en los informes de la memoria, identificando que de la esencia de la material sigue siendo el mismo, aunque transformado por la experiencia del terapeuta.

Palabras clave: psicoterapia; grabación en audio; presentación de informes; psicoanálisis.

Que tipo de registro retrata com mais proximidade o que ocorre em uma sessão de psicoterapia psicanalítica? Seria uma gravação em áudio, em que o ouvinte teria acesso total aos conteúdos abordados, à ordem em que cada assunto 
emergiu, ao que foi dito tanto pelo paciente como pelo psicoterapeuta? Ou quem sabe a transcrição deste áudio, auxiliando o pesquisador por oferecer um suporte visual ao material? Ou, ainda, o que mais aproximaria desta experiência singular e subjetiva seria um relato, feito a partir da memória do psicoterapeuta, que complementaria a descrição dos fatos e assuntos abordados com sentimentos, impressões e fantasias que inundaram sua mente no decorrer da própria sessão?

Apesar de aparentemente simples, esses questionamentos são a mola propulsora para este estudo a respeito de registros de sessóes de psicoterapia, mostrando quão importante e enriquecedor é o tema para um grupo de pesquisa que visa compreender profunda e cientificamente o que ocorre em uma sessão de psicoterapia psicanalítica. Sem a intenção de privilegiar um tipo de registro específico, nosso objetivo é assinalar empiricamente quais as especificidades do registro em áudio da sessão, da transcrição deste e da sessão relatada pela memória do psicoterapeuta.

Os relatos de caso a partir da memória do psicoterapeuta vêm sendo, tradicionalmente, o material de base para aprendizagem da psicoterapia. É a partir deste relato reconstruído que são realizadas as supervisóes necessárias na maioria dos contextos da prática clínica: experiência em estágios, cursos de formação de psicoterapeutas, formação psicanalítica. Bucci (2007) refere que os relatos de casos têm sido a base de dados para pesquisas e estudos de processo em psicoterapia. Ainda que este tipo de método ainda seja necessário, destaca suas limitaçóes, pois cita a tendenciosidade e a perda de informaçóes devido às limitaçóes das observaçôes de um único analista que realiza o atendimento.

Foi a partir destas limitaçóes que segundo Bucci (2007) surgiu a aplicação de medidas objetivas, como as gravações em fita ou transcriçōes literais das sessóes de psicoterapia. Wallerstein e Sampson (1971) entendem que a gravação, com a permissão do paciente, concede um caráter permanente e público do material ao passo que o relato por parte do analista é algo privado da dupla. Além disso, os autores destacam que o áudio facilita a separação entre a responsabilidade terapêutica e a investigativa. Em relação a estas responsabilidades, terapêutica e investigativa, Freud (1912/1987) já advertia que pesquisa e tratamento são atividades que coincidem, entretanto algumas cautelas devem ser tomadas, pois, caso a investigação empírica fosse o foco central, o tratamento estaria fadado ao fracasso. Neste sentido, se o objetivo de entender teoricamente o paciente e a publicação do seu material torna-se o foco da atenção do analista, este deixa de ter sua atenção flutuante aos aspectos inconscientes do paciente, prejudicando, assim, o tratamento. Ao escrever sobre o contrato, Etchegoyen (1989) defendeu o uso do gravador como mais um recurso, por parte do analista, para registrar o 
trabalho e ter a oportunidade de estudá-lo. De modo semelhante, pesquisadores como Domingues e Serralta (2005), Kächele, Thomä, Ruberg e Grünzig (1988), Peuker, Habigzang, Koller e Araujo (2009), Yoshida (1998) e Urwin (2006) consideraram o gravador como um aliado para a ampliação dos conhecimentos da psicanálise. Yoshida (1998), Urwin (2006) e Peuker et al. (2009) destacaram que uma das vantagens da utilização de gravaçóes é o fato de possibilitarem um estudo mais profundo e preciso do que efetivamente se passou na sessão. $\mathrm{O}$ uso da gravação em áudio ou vídeo possibilita uma compreensão mais acurada da sessão, podendo ser exaustivamente estudada pelo próprio terapeuta e, também, por juízes independentes (Yoshida, 1998). Domingues e Serralta (2005, p. 175) referiram que a gravação das sessóes permite, em longo prazo, "uma investigação longitudinal em profundidade do processo terapêutico" e o "automonitoramento dos terapeutas".

Psicoterapeutas costumam ter receio de utilizarem-se deste artifício pelo temor da exposição do paciente e de uma interferência negativa no processo psicoterápico, bem como no desenvolvimento da aliança terapêutica. Essa interferência costuma gerar ansiedade nos terapeutas, os quais temem a possibilidade de o paciente ficar ansioso e não permitir a gravação. Por estes motivos, a necessidade da gravação das sessóes já foi constatada como segunda causa mais recorrente da negativa de terapeutas para a participação em estudos de processo de psicoterapia (Vachon et al., 1995). Porém, de acordo com Domingues e Serralta (2005), a prática mostra um quadro diferente, no qual muitos terapeutas esquecem da presença do gravador e lidam com a ansiedade de forma produtiva. A presença do gravador na sessão foi discutida por Kächele et al. (1988) e Thomä e Kächele (1990). Estes autores referiram que a gravação das sessões em áudio foi rejeitada pela Psicanálise durante muito tempo, por diferentes razóes. Uma delas seria o receio de que a presença de um gravador na sessáo atuasse como um terceiro na relação transferencial, fazendo com que o paciente evitasse certos assuntos. Porém, de acordo com os autores, a gravação, uma vez acordada com o paciente, seria trabalhada como mais um elemento constante do enquadre, sobre cujo fundo será interpretado tudo que ocorre na sessão. A outra principal razão seria a exposição do terapeuta frente aos seus colegas de profissão. Mas este ponto, segundo os autores, seria um dos principais benefícios da gravação, pois propiciaria a criação de experiências de aprendizagem, viabilizando que o terapeuta se depare com sua atuação na sessão. Assim, os autores referem que a gravação parece incomodar mais a comunidade psicanalítica do que aos pacientes, e que, em sua longa experiência com gravaçóes, nunca encontraram resistências desencadeadas pelo gravador que fossem inacessíveis à interpretação. Ainda de acordo com Thomä 
e Kächele (1990), as anotaçóes feitas após a sessão, conforme recomendado por Freud, conduzem a uma seleção dos fenômenos que serão descritos pelo terapeuta, guiado por seus pontos de vista teóricos e por aspectos subjetivos. O gravador, por sua vez, é um receptor neutro, que não deixa nada sem ser ouvido e nem seleciona. Isso viabilizaria que pares (colegas, grupo de supervisão), ao terem contato com o material completo da sessão, pudessem fazer distintos recortes, ou enfatizar outros pontos, ou até mesmo compreender o recorte feito pelo terapeuta. Todavia, a temática da gravação de sessóes de psicoterapia está longe de encontrar um consenso. Klein (1961/1994, s/p) expressou-se veementemente contra este tipo de registro. Embora reconhecesse que um relato nem sempre poderia recordar literalmente as associaçóes do paciente, considerava que a utilização de um gravador seria "absolutamente contrário aos princípios fundamentais em que se baseia a psicanálise" em virtude da privacidade do material. Além disso, considerava que nem o paciente e nem o terapeuta se comportariam da mesma forma que o fazem quando estão sozinhos.

Ainda que Freud (1912/1987) não tenha mencionado nada especificamente quanto à gravação do material, ele matinha uma ideia parecida com a de Klein (1961/1964), sugerindo fortemente que os analistas não fizessem anotações durante as sessões, pois defendia a ideia de que relatórios exatos de histórias clínicas analíticas têm um valor menor por terem uma "exatidão ostensiva" (Freud, 1912/1987, p. 127). Ele compreendia que haveria uma limitação quanto à memória do analista em relação ao caso. Acreditava, contudo, que a comunicação se dava de inconsciente para inconsciente, destacando que o papel efetivo da memória consciente pouco auxiliaria na captação do material inconsciente do paciente. Em um estado de escuta em que o psicanalista procura estar com uma atençáo flutuante, a memória só atrapalharia o fluxo de pensamento que conduz à verdade inconsciente do paciente. No entanto, a memória não está totalmente fora do processo. Freud destacou que o analista apresenta uma "memória inconsciente" dos fatos que o paciente traz, o que frequentemente causa espanto aos pacientes: como o médico lembra de detalhes tão acurados de algo que lhe fora dito há muito tempo?

Reconhecendo o desafio contido na tarefa de informar com exatidão o que se passou durante o atendimento com o paciente, Winnicott (1971/1984, p. 11) destacou que o uso de gravaçóes em áudio ou em vídeo não resolveria o problema da exatidão. Para diminuir esta dificuldade ele descreveu que fazia anotaçôes de tudo o que ocorria ao longo da sessáo, inclusive pensamentos e sentimentos por ele vivenciados, deparando-se no fim com a reconstrução "da quase totalidade da entrevista". Conforme o autor, se estes detalhes importantes da sessão não fossem descritos imediatamente, em um curto período de tempo após a sessão, estariam 
fadados a serem esquecidos, assim como os sonhos que escapam de nossa consciência ao nascer do dia. Apesar de defenderem o uso da gravação, Wallerstein e Sampson (1971) reconhecem a riqueza de quando um material é relatado da memória de um analista treinado e que conhece longitudinalmente o caso. Nestes casos, destacam que a leitura do material é mais curta e densa, e que apresenta a essência do caso, auxiliando a compreensão longitudinal do processo. Além disso, nos relatos há espaço para a expressão e registro em palavra sobre os aspectos transferenciais e contratransferenciais sentidos e entendidos pelo analista. Nesse sentido, defendem também este tipo de material para pesquisa. Thomä e Kächele (1990) também destacam a riqueza do relato, argumentando que, em contrapartida, é bastante cansativo ler uma transcrição muito literal de uma sessão, sem retoques na redação. Além disto, as transcriçôes podem parecer muito pobres em comparação às recordaçóes que o terapeuta tem da sessão, pois muitos pensamentos e emoçôes não são ditos e, portanto, não são captados por um gravador.

\section{Um estudo sobre as formas de registro de sessáo}

Este artigo é derivado do material coletado para uma pesquisa mais ampla (Silva, Hallberg, Steibel \& Campezatto, 2010) que tem como base as sessóes de atendimento gravadas em áudio no primeiro ano de tratamento em psicoterapia psicanalítica de três pacientes. Os casos são supervisionados semanalmente pelo grupo de pesquisa, formado por uma psicanalista experiente (supervisora), uma professora-pesquisadora em psicologia e psicanálise, quatro psicólogas com experiência em psicoterapia (dentre estas a terapeuta do caso) e duas estudantes de psicologia. Para este estudo serão utilizados dados do primeiro caso de atendido.

Tendo em vista os devidos cuidados éticos, o paciente em questão foi convidado a participar da pesquisa logo após a triagem, a qual é o procedimento padrão de acolhida dos pacientes na instituição parceira deste estudo, que é um instituto de ensino e pesquisa em psicoterapia psicanalítica. Nesse momento, foi explicado, em linhas gerais, o objetivo da pesquisa e a necessidade de gravação em áudio. Após o aceite do paciente, foi solicitada a assinatura do Termo de Consentimento Livre e Esclarecido e só depois se iniciou o tratamento. O projeto do qual faz parte este artigo foi aprovado pelo Comitê de Ética em Pesquisa do Instituto de Psicologia da UFRGS sob o protocolo no 2010060.

Todas as sessóes da psicoterapia foram gravadas e transcritas. Inicialmente, as transcriçôes eram utilizadas como material de supervisão. Porém, conforme descrito em outro artigo (Silva, Hallberg, Steibel, Campezatto \& Klarmann, 
2011), a dificuldade em supervisionar o material transcrito levou o grupo a utilizar, em um segundo momento, o relato realizado pela própria terapeuta do caso a partir de sua memória. Nesse novo formato, o grupo mostrou-se mais próximo da dupla terapeuta-paciente, adquirindo também maior fluidez no trabalho de supervisão devido à vivacidade dos relatos supervisionados. A partir disso, houve alguns momentos nos quais a terapeuta não se lembrava de algum fato relatado pelo paciente, e o colega que estava fazendo a transcrição da gravação complementava as lacunas de memória da terapeuta. Este fenômeno ocasionou diversas reflexóes por parte do grupo, como os motivos de tanta diferença entre o relato que chamamos "real" (transcrição da gravação), a escuta do áudio e o relato "vivencial” (a partir da memória da terapeuta) (Silva et al., 2011).

A partir desta experiência e dos questionamentos que emergiram, realizou-se o presente estudo, que teve por finalidade assinalar empiricamente se há diferenças e, havendo, quais as especificidades do registro em áudio, da transcrição de áudio e do relato pela memória do psicoterapeuta.

\section{Método}

As sessóes analisadas

A fonte de informações é oriunda de três sessôes consecutivas do tratamento em psicoterapia psicanalítica. A escolha das sessóes se deu por conveniência, escolhendo-se as três primeiras sessóes que contivessem os três tipos de registro completos (gravação em áudio, transcrição e relato de memória do terapeuta).

\section{Informaçóes sobre a paciente e a terapeuta}

A paciente do caso em questão é uma mulher com 19 anos de idade. Esta é empregada doméstica e chegou à instituição por indicação de uma amiga. A terapeuta é psicóloga, especialista em psicoterapia psicanalítica e psicanalista em formação.

\section{Análise dos dados}

$\mathrm{O}$ estudo segue a abordagem qualitativa de pesquisa. O objetivo desta não é a generalizaçấo dos dados, visto que a sua relevância científica encontra-se 
no entendimento das particularidades de cada material analisado, buscando a complexidade do fenômeno (Minayo, 1999). Os dados foram analisados através da análise categorial de acordo com Bardin (1977/2007), procedimento que consiste em operaçóes de desdobramento do texto em unidades com o intuito de descobrir os diferentes núcleos de sentido que constituem a comunicação e posteriormente realizar o seu agrupamento em classes ou categorias. Os registros das sessóes foram divididos entre os membros do grupo, composto por uma psicanalista experiente (supervisora), uma professora-pesquisadora em psicologia e psicanálise, quatro psicólogas com experiência em psicoterapia (dentre estas a terapeuta do caso) e duas estudantes de psicologia, de forma que cada integrante recebesse uma sessão em cada forma de registro e que nenhum tipo de registro fosse analisado por apenas um pesquisador. Foi solicitado que cada pesquisador tivesse contato com o material e listasse os assuntos da sessão. Depois de levantados estes assuntos, buscou-se comparar os resultados obtidos. Desta forma, foi desenvolvida uma tabela comparando os assuntos presentes no relato elaborado a partir da memória do terapeuta, transcrição e na gravação em áudio. Após esta comparação verificou-se que os resultados obtidos eram muito semelhantes nas três sessóes analisadas. A partir disso, o grupo optou pela escolha de uma das sessōes, buscando vislumbrar com maior profundidade as sutis diferenças que se estabeleceram entre os registros.

\section{Discussão dos resultados}

A partir do material analisado, foram construídas três categorias de resultados: Diferenças de conteúdos entre os registros; Especificidades do relato de memória da terapeuta; e Sutis diferenças entre transcrição do áudio, áudio e relato de memória da terapeuta. Estas três categorias serão explanadas a seguir:

\section{Diferenças de conteúdos entre os registros}

A análise deste material demonstrou que os principais conteúdos foram listados nos três tipos de registros, embora a sessão relatada pela memória da terapeuta tenha apresentado uma ordem diferente das demais. Quanto a esse aspecto, compreendeu-se que a ordem de desenvolvimento náo comprometeu a essência do material, aspecto que corrobora o que Wallerstein e Sampson (1971) apontaram quanto à essência rica do material relatado pela memória do terapeuta. 
Observou-se, em um primeiro momento, que a transcrição da sessão apresentou um maior número de conteúdos do que o relato de memória da terapeuta. Quanto a este aspecto, a transcrição continha tanto conteúdos excluídos do relato como, também, vários conteúdos relacionados ao mesmo tema que apareceram de forma sintética no relato. Este aspecto pode ocorrer em virtude de a transcrição ser mais detalhada do que o relato, ou seja, muitos conteúdos que são diferenciados na transcrição acabam sendo unidos no relato do terapeuta. Na transcrição do áudio da sessão analisada, por exemplo, estáo presentes diversos conteúdos sobre a relação da paciente com uma amiga (sentimento em relação à família da amiga, onde a amiga trabalha, as atividades da amiga, reconhecimento da continuidade do vínculo com a amiga, entre outros) enquanto, no relato de memória da terapeuta, esses diversos conteúdos não aparecem de forma detalhada, mas sim unidos em um diálogo sintético, abrangendo apenas as categorias de descriçáo do relacionamento com a amiga e possibilidade da continuidade do vínculo com esta. Segue uma ilustraçáo retirada do relato de memória:

P - ... Mas quando a [amiga] foi embora [do trabalho] eu disse para ela o quanto ela era importante e que ela era uma amiga de verdade.

$\mathrm{T}$ - Tu sente falta da [amiga], né?

P - Muito, desde que ela foi embora sinto muito, é que ela foi a única que me ajudou. Conversava comigo, me escutava.

$\mathrm{T}$ - E tu náo falou mais com ela depois que ela saiu?

$\mathrm{P}$ - Falo com ela todos os dias, às vezes vou na casa dela, nos fins de semana, e fico ali com os filhos dela. Ai que horror, também eu fiz um drama quando ela foi embora, parecia que nunca mais ia ver ela, e agora ta aí. Tempestade em um copo de água, seguimos nos falando.

$\mathrm{T}$ - Porque tu diz que é uma tempestade em um copo d'água?

$\mathrm{P}$ - Porque foi um exagero.

$\mathrm{T}$ - É que agora tu sabe que vocês podem seguir se falando mesmo ela não estando junto contigo, talvez antes tu não sabia disso.

$\mathrm{P}$-É. Mas é que eu sempre tive dificuldade também com os sentimentos, nunca consigo dizer para as pessoas que eu gosto delas, não sei porquê...

Nesse trecho é possível pensar que a essência do material é o que fica registrado na mente da terapeuta. Esta, já compreendendo a relação transferencial estabelecida e a forma de se relacionar característica da paciente, não descreve exaustivamente o diálogo, mas sim o que este estava representando. Também po- 
demos perceber que apareceram na transcrição literal do áudio diversas queixas físicas, tais como insônia, o fato de a paciente não se alimentar corretamente, referir que voltou a chorar e o uso de medicaçáo sem prescrição desencadeando efeitos colaterais. Tais aspectos não apareceram no relato de memória. Compreende-se que a terapeuta, ao tentar reproduzir a sessão em suas palavras, realiza uma seleção de conteúdos, feita de forma consciente e inconsciente. Um estudo sobre o processo psicoterápico poderia auxiliar na elucidação do porquê desta seleção natural. Inclusive, estes lapsos são considerados pela psicanálise como parte da riqueza do material, apontando para uma forma de comunicaçáo do sofrimento psíquico. Sendo assim, o que aparentemente poderia ser considerada uma limitação pode, se bem utilizado, servir para ampliar a compreensão do campo psicoterápico presente entre a dupla terapeuta-paciente.

Outro aspecto que se faz presente na leitura da transcrição da gravação é a possibilidade de acompanhar com detalhes a associação de ideias e de intervenções ocorridas na sessão, conforme ilustrado abaixo:

P: É! A gente fica, sabe...? Me sinto usada, sabe? Porque antes eu falava "ah [patroa] eu nunca, bem capaz, eu não vou sair daqui, bem capaz”. Mas agora sim. Aí, sei lá... se eu não tiver coragem eu falo qualquer coisa, que eu recebi uma proposta, que o salário é melhor, que eu tenho que fazer menos coisas e tal...

T: E por que tu não teria coragem?

P: Pois, é... eu acho que eu sou meio [suspiro] um pouquinho covarde ainda...

T: Não, não é covarde, eu acho que às vezes tu fica... até pode te sentir um pouco culpada por não falar as coisas, ou até covarde, né, mas que é difícil pra ti te impor...

P: É...

T: Claro que acho que tu gostaria que ela te valorizasse, mas até pra tu poder contra-argumentar com ela... é complicado pra ti, não é? Tu te sente inadequada...

P: Ahm!

T: Como se tu tivesse errada, ou se ela só que fosse a certa...

P: É!

T: E parece que o único jeito que tu tem de dar o troco pra ela, entre aspas, seria te mandar de lá e deixar ela na mão.

P: É verdade! É o que eu... assim, um dia que veio o irmão dela... ela sabe, assim, ela sempre manda eu ir dormir no quarto das crianças. Aí ela me fez 
ficar acordada até onze, onze e meia, sentada ali no escritório esperando. Depois ela chegou "ah, tu dorme ali no quarto das crianças, tá?”.

Nessa sequência da sessão transcrita a partir da gravação em áudio, tem-se a oportunidade de acompanhar na íntegra as sucessivas tentativas da terapeuta de interpretar as respostas da paciente. Percebe-se que, inicialmente, as interpretaçóes não atingem a paciente de forma que ela utilize estas para associar e pensar, apesar de ter aceitado verbalmente as interpretaçóes, concordando sem refletir, através de "aham" e "sim". Já no fim do exemplo, quando a terapeuta consegue interpretar de forma mais direta o afeto, sugerindo de forma implícita a raiva e a consequente vontade de sair do emprego, a paciente aceita e segue associando e pensando. Nesse sentido, a transcrição assume um papel importante quando o objetivo é pesquisar o processo terapêutico, pois o pesquisador pode debruçar-se sobre a sequência de ideias da dupla e estudar a dinâmica desta. Segundo Urwin (2006), formas de registro como vídeo, áudio e transcrição possibilitam que os terapeutas/pesquisadores possam se aprofundar na livre associação de ideias do paciente, de forma que possam pensar em outras significações e interpretaçóes.

\section{Especificidades do relato de memória da terapeuta}

Um aspecto observado foi que o relato de memória do terapeuta era mais completo no sentido de incluir contextualizaçóes que aproximavam as pesquisadoras do conteúdo emocional das sessóes. Tais contextualizaçóes incluíam o relato de contatos extrassessão, pensamentos do terapeuta relacionados a outras sessóes e à história da paciente, além de sentimentos contratransferenciais que davam vivacidade ao material e possibilitavam uma maior aproximação dos pesquisadores aos aspectos não-ditos presentes na sessão. Com base nisso, podemos pensar sobre os aspectos não verbais contidos em uma sessão de psicoterapia e sobre sua importância para o êxito de um tratamento. Estes aspectos não verbais, por vezes denominados de enactments, incluem aqueles que lutam por serem simbolizados e que acabam por emergir nas entrelinhas do discurso verbal, nos gestos, nos olhares. São descargas que ocorrem na relação analítica e que normalmente se manifestam como comportamentos e açóes da dupla analítica (Cassorla, 2007).

$\mathrm{Na}$ transcrição do áudio, aparece o atraso da paciente para a sessão como um conteúdo, representando a seguinte expressão: “Me atrasei um pouquinho. 
[risos]". No entanto, no relato está presente o sentimento da terapeuta em relaçáo ao atraso. A terapeuta inicia o relato de memória do atendimento analisado referindo ter tentado realizar um contato com a paciente fora da sessão. Tenta telefonar e, ao não ser atendida, envia uma mensagem telefônica confirmando a data e o horário do atendimento. Sem obter resposta e, ao não encontrar a paciente aguardando-a em seu horário, complementa o relato: "Me dou por vencida, acredito que ela não virá e que nunca mais fará contato. Então me disperso com outros afazeres. Passando 10 minutos do seu horário sou surpreendida por uma voz dizendo para a secretária que ela teria um horário agora. Fico muito surpresa, pois já havia desistido da ideia dela vir à sessão. Entramos na sala e ela diz que se atrasou”.

Apesar de o conteúdo ser basicamente o mesmo, percebe-se que a descrição do sentimento da terapeuta aproxima o leitor/pesquisador do conteúdo emocional e transferencial da dupla terapêutica. O contato com esse tipo de contextualização e sentimento demonstra o quanto informações extratranscrição são necessárias e auxiliam na compreensão dinâmica do caso em questão. A ideia de que uma transcrição da gravação de sessão contempla a totalidade de assuntos se desfaz, uma vez que um tratamento psicoterápico inclui muitas situaçóes como esta. $\mathrm{O}$ complemento da transcrição mostra-se necessário, seja no formato de relato das entrevistas por memória da terapeuta, seja na forma de um diário de campo do pesquisador/psicoterapeuta. A passagem a seguir, extraída do relato de memória, também ilustra pensamentos da terapeuta complementares à transcrição do áudio:

A sessão vai encerrando e dentro de mim tenho uma convicção de que teria acabado a avaliação [...] mas que agora parece que eu entendo que ela "quer" [o tratamento], só resta a dúvida se ela vai conseguir, mas isso já faz parte do tratamento. Então digo, com segurança, que aguardo ela na semana que vem.

Domingues e Serralta (2005) referem que uma limitação da supervisão dos dados gravados é que estes vêm crus. Thomä e Kächele (1990) também ponderam que é bastante cansativo ler uma transcrição muito literal de uma sessão, sem retoques na redação, além de ser impossível supervisionar este material em um horário limitado devido à grande extensão deste (Silva et al., 2011). Além disto, muitos pensamentos e emoçóes não são ditos e, portanto, não são captados por este instrumento técnico. Por isso, às vezes as transcrições parecem muito pobres em comparação às recordações que o terapeuta tem da sessão. 
Assim, é necessário que o terapeuta faça um registro de seus sentimentos e dos não-ditos percebidos por ele logo após a sessáo de modo a complementar o material gravado. Neste sentido, o recurso da sessão gravada em áudio também pode suprir esta lacuna do material transcrito, pois ajuda o pesquisador a sentir o clima da sessão através de tonalidade, ritmos, interrupçóes, silêncios entre outras situações não verbais.

\section{Sutis diferenças entre transcriçáo do áudio, áudio e relato de memória do terapeuta}

Um terceiro aspecto observado foi uma sutil diferença em como eram trazidos assuntos pelas palavras transcritas e pela terapeuta. Para elucidar este aspecto, o grupo escutou coletivamente a gravação em áudio da sessão em estudo buscando compreender e elaborar hipóteses a respeito destas diferenças. Na transcrição do áudio e na gravação do mesmo, aparece uma confusão no discurso da paciente, que muitas vezes não termina as suas frases e pensamentos, como a seguir:

P: É... coisa que... até ah... eu liguei pra essa escola, é NEJA o nome que a gente vai, só que é classificatório. Aí é o dia 15. Só que, assim, eu to pensando, assim, dar uma enrolada e não ir agora, porque até porque se eu sair eu tenho, de repente pro... pra que lugar eu vou... pra mim, sei lá, de repente eu ia pra coisa.

No relato de memória da terapeuta, as lacunas no discurso não são reproduzidas. Todavia, o que se faz presente é um sentimento contratransferencial de confusão:

Fico confusa o que teria a ver comigo esta questão de se sentir abusada, mas temo em abusar dela e que ela saia correndo, pois sinto que esta seria a "desculpa" dela para não se vincular a nada. Fico todo tempo pensando na fragilidade que é a nossa relação ali, mas embora já tenha dito uma ou duas vezes durante a sessão, sinto que seria difícil trabalhar isso com ela.

Outro aspecto que não aparece da mesma forma no relato de memória e na transcrição do material gravado é a ambivalência sentida pela paciente em relação à patroa. $\mathrm{Na}$ transcrição, além de aparecer um desejo de não fazer as tarefas domésticas por sentir-se sobrecarregada, aparece também o desejo de 
que cuidar das crianças fosse a tarefa principal de seu trabalho, como ilustra o seguinte exemplo:

P: Chega com sacolas em casa, e é roupa pros filhos, e é tudo de marca [...]. Então... tá sobrando, né? [...] É, é isso, sabe? Se fosse só cuidar deles, assim, nossa, poderia, assim, me estressar um monte que eu não ia me importar, porque eu gosto de criança, assim. E eu não tenho tempo nem pra brincar...

No relato de memória da terapeuta, por sua vez, é priorizada a descrição de um sentimento de inveja da paciente em relação às compras da patroa e ao seu dinheiro, não sendo o conteúdo mencionado o restante da frase reproduzida acima. Parece que a terapeuta seleciona inconscientemente este conteúdo, destacando o sentimento de inveja que a paciente demonstra em relação à patroa ${ }^{1}$. Porém compreende-se que, em contrapartida à inveja, há o sentimento infantil de desejar ser filha da patroa, podendo brincar com e como os filhos desta, sendo estes conteúdos - excluídos do relato - também importantes. No decorrer da sessão, a terapeuta não conseguiu se conectar com ambos os lados de um mesmo conteúdo trazido pela paciente, prejudicando sua percepção, que não estava de acordo com a "visão binocular" denominada por Bion (1967/1994). O autor descreve que frente à parte psicótica (posição esquizoparanoide) e neurótica (posição depressiva) da personalidade, o analista deve manter-se sempre mudando de vértice para que possa ter uma visão mais global da personalidade do paciente. No entanto, na relação dinâmica entre paciente e terapeuta, isso nem sempre é possível, e o terapeuta, engolfado na dinâmica do paciente, perde sua visão binocular. Neste caso, após tomar contato com o material transcrito, a terapeuta teve a oportunidade de se aproximar desta dissociação, percebendo a sessão de forma mais completa. Assim, o trabalho com os três tipos de registro pode servir como instrumento para a tomada de contato com diferentes vértices de uma determinada experiência emocional, quando esta não é possível no decorrer da sessão. Ainda pode-se destacar que, na transcrição do material gravado, aparece a ambivalência da paciente em relação ao trabalho, mas no relato a terapeuta escreve que a ambivalência se dá em relação à patroa. Um exemplo da transcrição: "Apesar ah... que eu fico lá, eu não preciso pagar aluguel, eu não preciso pagar comida. Mas... é muito pouco. Pelo que eu tenho que fazer, assim, tô muito desanimada, né, assim. Faz tempo...”.

Considera-se que no relato a terapeuta já transforma o que a paciente disse na sessão, interpretando que o manifesto expressado na fala da paciente é a relação de objeto com a patroa. A partir dessa transformação interna da terapeuta, esta 
produz um relato de acordo com sua vivência, que passa a ser o registro "real" para a terapeuta. Dessa forma, salienta-se que, ainda que os conteúdos expressos nos registros sejam aparentemente diferentes, seu conteúdo latente (sua essência) é basicamente o mesmo.

\section{Consideraçóes finais}

A partir do material estudado, contatou-se que os três tipos de registros apresentam diferenças significativas entre si, sendo complementares, e não excludentes, para a apreensão do material em questão. Nenhum deles foi percebido como melhor dos que os demais. Cada tipo de registro traz uma riqueza e privilegia alguns aspectos, de modo que a escolha deve se dar de acordo com os objetivos da utilização.

Para a supervisão de casos em psicoterapia de orientação psicanalítica, por exemplo, o relato de memória do psicoterapeuta parece ser o mais prático e útil. Embora mais enxuto que a transcrição e não tão fiel à literalidade do material, no caso analisado o relato não mostrou uma perda dos conteúdos trazidos pela paciente a ponto de prejudicar o andamento do caso. Além disso, a experiência emocional do terapeuta em relação ao seu paciente e sua leitura do campo transferencial são aspectos mais importantes para a direção do tratamento do que dados com "exatidão ostensiva” (Freud, 1912/1987, p. 127). Neste sentido, este trabalho pôde ilustrar como ocorre o processo de transformação do terapeuta a partir do material escutado. Este, no relato, apresenta uma leitura própria do seu paciente e da transferência, ao passo que, na íntegra da sessão (transcrição ou áudio), estes conteúdos vão aparecer como matéria bruta, não lapidada.

No entanto, existem diferenças entre os terapeutas (de formação, experiência, interesses teóricos), sendo possível pensar que alguns relatos possam não ser boas descriçóes do que ocorreu em uma sessão de psicoterapia. A gravação e a transcrição podem ser recursos extras utilizados para o terapeuta perceber possíveis cisóes e lapsos de memória ao longo das sessóes, sendo mais uma forma de pensar o material, o paciente e a sua própria prática profissional. Neste sentido, entende-se que a gravação pode servir como um recurso didático para terapeutas em formação, os quais poderiam ouvir suas próprias sessóes e/ou ter acesso a sessóes de psicoterapia de outros profissionais e discuti-las com professores e supervisores.

Para fins de pesquisa, destaca-se a importância de o pesquisador poder circular pelas diferentes formas de registros, principalmente quando o objeto de 
pesquisa se refere ao processo da psicoterapia. O olhar através de diferentes vértices viabilizaria a melhor aproximação possível da difícil tarefa de apreender o que se passa entre terapeuta e paciente. Esta seria uma forma de atender a uma das recomendações de Freud (1912/1987, p. 128) que já indicava a necessidade de o analista "oscilar, de acordo com a necessidade, de uma atitude mental para outra".

\section{Referências}

Bardin, L. (2007). Análise de conteúdo. Lisboa: Ediçôes 70. (Obra original publicada em 1977). Bion, W. (1994). Estudos psicanalíticos revisados. Rio de Janeiro: Imago. (Obra original publicada em 1967).

Bucci, W. (2007) Pesquisa sobre processo. In E. S. Person, A. M. Cooper \& G. O. Gabbard. (Eds.). Compêndio de Psicanálise (pp. 320-336). Porto Alegre: Artmed.

Cassorla, R. M. S. (2007). Do baluarte ao enactment: o "não-sonho" no teatro da análise. Revista Brasileira de Psicanálise, 41(3), 51-68.

Domingues, A. E., \& Serralta, F. B. (2005). O uso do gravador na psicoterapia de orientação psicanalítica: o ponto de vista do psicoterapeuta. Revista Brasileira de Psicoterapia, 7(2-3), 169-182.

Etchegoyen, R. H. (1989). Fundamentos da técnica psicanalitica. Porto Alegre: Artmed.

Freud, S. (1987). Recomendações aos médicos que exercem a psicanálise. In S. Freud. Edição standard brasileira das obras psicológicas completas de Sigmund Freud, v. XII. Rio de Janeiro: Imago. (Obra original publicada em 1912).

Kächele, H., Thomä, H., Ruberg, W., \& Grünzig, H. (1988). Audio-recordings of the psychoanalytic dialogue: Scientific, clinical and ethical problems. In H. Dahl, H. Kächele \& H. Thomä (Eds). Psychoanalytic process research strategies (pp. 179-193). Berlin: Springer 1988.

Klein, M. (1994). Narrativa da análise de uma criança. Rio de Janeiro: Imago. (Obra original publicada em 1961).

Minayo, M. C. S (1999). O desafio do conhecimento: pesquisa qualitativa em saúde. São Paulo: Hucitec.

Peuker, A. C., Habigzang, L. F., Koller, S. H., \& Araujo, L. B. (2009). Avaliação de processo e resultado em psicoterapias: uma revisão. Psicologia em Estudo, 14(3), 439-445.

Silva, M. R., Hallberg, A. E., Steibel, D., \& Campezatto, P. V. M. (2010). A resistência no início do tratamento - estudo do processo da psicoterapia psicanalítica. Projeto de pesquisa não publicado.

Silva, M. R., Hallberg, A. E., Steibel, D., Campezatto, P. V. M., \& Klarmann, R. P. (2011). A apresentação do material clínico na supervisão coletiva: um relato de experiência. Psicoterapia Psicanalitica, 13, 153-164. 
Thomä, H., \& Kächele, H. (1990). Teoria y prática del psicoanálisis - Tomo 2: Estudios Clinicos. Barcelona: Editorial Herder.

Urwin, C. (2006). Exploring the unexpected: Transference phenomena in a research setting. Infant Observation: International Journal of Infant Observation and Its Applications, 9(2), 165-177.

Vachon, D. O., Susman, M., Wynne, M. E., Birringer, J., Olshefsky, L., \& Cox, K. (1995). Reasons therapists give for refusing to participate in psychotherapy process research. Journal of Counseling Psychology, 42(3), 380-382.

Yoshida, E. M. P. (1998). Avaliação de mudança em processos terapêuticos. Psicologia Escolar e Educacional, 2(2), 115-127.

Wallerstein, R. S., \& Sampson, H. (1971). Issues in research in the psychoanalytic process. International Journal Psycho-Analysis, 52, 11-50.

Winnicott, D. (1984). Consultas terapêuticas em psiquiatria infantil. Rio de Janeiro: Imago. (Obra original publicada em 1971).

\section{Nota}

${ }^{1}$ É claro que o contexto socioeconômico da paciente precisa ser levado em consideração, uma vez que se trata de uma jovem empregada doméstica. A chegada da patroa com sacolas de compras defronta-a com a imensa desigualdade de renda entre ela e a patroa. Reflete, assim, a desigualdade social existente no Brasil, em que algumas poucas pessoas têm um poder aquisitivo muito maior do que o da maioria da população. De qualquer forma, essa desigualdade mobiliza um sentimento de inveja por parte da paciente, o qual, com a devida contextualização, pode ser foco de atenção clínica.

Recebido em 11 de dezembro de 2012 Aceito para publicação em 03 de outubro de 2013 